the doctor or manufacturer of the vaccine could not be considered to have been negligent. Nevertheless, unless a no fault compensation scheme is established such cases are likely to entail parents in considerable expense over a prolonged period and create considerable adverse publicity for rubella vaccination. Indeed, this has occurred recently; it would be unfortunate if such adverse publicity destroys the public's confidence in a remarkably effective and safe vaccine.

The selective rubella vaccination programme in the United Kingdom was recently augmented by the introduction of a combined measles, mumps, and rubella vaccine for children of both sexes. ${ }^{18}$ Although this programme will reduce the circulation of rubella in the community and thereby decrease the risk of exposure of pregnant women to the virus, cases of reinfection will probably continue to be diagnosed for some years. Until rubella infection is eradicated consideration must be given to testing all pregnant women who have contact with or develop illnesses like rubella, even if they have a history of rubella vaccination and have been reported previously to have rubella antibodies.

We thank Dr S F Pugh and Miss J L Baker (University Hospital, Nottingham), Mrs J A Shirley and Dr T H Flewett (Regional Virus Laboratory, Birmingham), Dr B Chattopadhyay (Whipps Cross Hospital, London), Dr M Sharland and $\mathrm{Dr} W$ Lenney (Roval Alexandra Hospital for Sick Children, Brighton), and Dr A A Saeed (St Mary's General Hospital, Portsmouth), who have allowed us to report their cases and have been most helpful in supplying additional information. We also thank the staff of our laboratories, and Dr P Grint of the department of virology at St Bartholomew's Hospital for their help.
I Cradock-Watson JE, Ridehalgh MKS, Anderson MJ, Pattison JR, Rubella reinfection and the ferus. Lancet 1985;ii: 1039

2 Morgan-Capner P. Hodgson J, Hambling MH, et al. Detection of rubellaspecific IgM in subclinical rubella reinfection in pregnancy. Lancet $1985 ;$; $244-6$

3 Morgan-Capner P. Does rubella reinfection matter? In: Mortimer PP, ed. Public health virologv, 12 reports. London: Public Health Laboratory Service, 1986:50-62

4 Best JM, O'Shea S. Rubella. In: Schmidt NJ, Emmons RW, eds. Diagnostic procedures for viral, rickettsial and chlamvdial infections. 6 th ed. Washington, DC: American Public Health Asseciation, 1989:731-95.

5 Thomas HIJ, Morgan-Capner P. Rubella-specific IgG subclass avidity ELISA and its role in the differentiation between primary rubella and rubella reinfection. Epidemiol Infect 1988;101:591-8.

6 Forsgren M, Carlstrom G, Strangert K. Congenital rubella after maternal reinfection. Scand F Infect Dis 1979;11:81-3.

Bott LM, Eizenberg DH. Congenital rubella after successful vaccination. Med F A ust 1982;i:514-5.

8 Enders G, Calm A, Schaub J. Rubella embryopathy after previous maternal rubella vaccination. Infection 1984;12:96-8.

9 Forsgren $M$, Soren $L$. Subclinical rubella reinfection in vaccinated women with rubella-specific $\operatorname{IgM}$ response during pregnancy and transmission of virus to the fetus. Scand I Infect Dis 1985;17:337-41.

10 Horstein L, Levy U, Fogel A. Clinical rubella with virus transmission to the fetus in a pregnant woman considered to be immune. $N$ Engl $f \mathrm{Med}$ 1988;319:1415-6.

11 Best JM, Welch JM, Baker DA, Banatvala JE. Maternal rubella at St Thomas' Hospital in 1978 and 1986: support for augmenting the rubella vaccination programme. Lancet 1987;ii:88-90.

12 Morgan-Capner P, Rodeck CH, Nicolaides K, Cradock-Watson JE. Prenatal diagnosis of rubella. Lancet $1984 ;$ ii: 343 .

13 Enders G, Jonatha W. Prenatal diagnosis of intrauterine rubella. Infection $1988 ; 15: 162-4$

14 Ho-Terry L, Terry GM, Londesborough P, Rees KR, Wielaard F, Denissen A. Diagnosis of fetal rubella infection by nucleic acid hybridization. 7 Med Virol 1988:24:175-82.

15 Erlich HA, Gelfand DH, Saiki RK. Specific DNA amplification. Nature 1988;331:461-2.

16 O'Shea S, Best JM, Banatvala JE. Viremia, virus excretion and antibody responses after challenge in volunteers with low levels of antibody to rubella virus. $\mathcal{F}$ Infect Dis 1983;148:639-47.

17 Stern H, Hannington G, Booth J, Moncrieff D. An early marker of fetal infection after primary cytomegalovirus infection in pregnancy. $\mathrm{Br} \mathrm{Med} \mathcal{f}$ 1986;292:718-20.

18 Badenoch J. Big bang for vaccination. Br Med f 1988;297:75f-1.

(Accepted 21 fuly 1989
Departments of

Haematology and

Microbiology, University

College and Middlesex

School of Medicine,

London W1P 7PN

S E Kinsey, MRCP, clinical

lecturer in haematology

J Holton, MRCPATH, senior

lecturer

F J Giles, MB, research fellow

Correspondence to: $\operatorname{Dr} S \mathrm{E}$ Kinsey.

Br Med f 1989;299:775-6

\section{Cusum plotting of temperature charts for assessing antimicrobial treatment in neutropenic patients}

\author{
S E Kinsey, F J Giles, J Holton
}

Patients with severe neutropenia are at risk of life threatening infection in proportion to their neutrophil count.' They are treated empirically on developing fever with a combination of broad spectrum antibacterial agents. The interpretation of their temperature charts, which are commonly chaotic, causes added confusion.

We compiled temperature charts for patients requiring antibiotics to assess the usefulness of cusum plotting in monitoring patients' progress and to determine the merit of modifying treatment during the febrile episode.

Cumulative sum (cusum) is a statistical manoeuvre that permits rapid analysis and identification of trends in a series of data. Cusum plots may be performed on any data gathered serially; their main use is in quality control in medical laboratories. ${ }^{2}$ Their value in analysing clinical data has been outlined. ${ }^{3.5}$ To apply cusum plots to temperature measurements a reference temperature is selected, which is subtracted from each successive temperature recording and the remainder (which may be positive or negative) is added arithmetically to the previous sum. This cumulative sum is plotted against time. If successive temperature readings are the same as the reference temperature the plot remains at zero; if the temperature rises or falls the plot does likewise. Changes to a sustained higher or lower temperature result in a plot with an upward or downward gradient respectively. In interpreting cusum plots changes in gradient (not plot height) and inflection points are important, but these may be disguised slightly by the reference temperature chosen.

\section{Patients, methods, and results}

We retrospectively analysed by cusum plots conventional temperature charts of 25 neutropenic patients (neutrophil count $<1 \cdot 0 \times 10^{9} / 1$ ) who had developed a fever. These were calculated in two ways. In 14 patients (group A) the reference temperature was calculated as the mean of five temperature readings before the fever; all subsequent values were then plotted as a cusum plot. In 11 patients (group B) we chose four reference temperatures $\left(37 \cdot 2{ }^{\circ} \mathrm{C}, 37 \cdot 6{ }^{\circ} \mathrm{C}\right.$, $38 \cdot 2^{\circ} \mathrm{C}$, and the mean of the first six febrile points); the cumulative sum was then continued with successive temperature recordings.

Of the 14 charts of patients in group $\mathrm{A}$, five showed a clear inflection associated with starting antimicrobial chemotherapy; no other useful information was obtained. Of the 11 charts of patients in group B, eight showed an association between starting treatment and resolution of the fever. In three patients the upward trend in temperature continued despite treatment and reversed only with an increasing granulocyte count $>1.0 \times 10^{9} / 1$. The trend was most easily interpreted with either $37.6^{\circ} \mathrm{C}$ or the mean of the first six temperature points during the fever as the reference. In five patients the cusum distribution showed clearly that the temperature trend was improving; further antimicrobial agents, however, had been given on the basis of a perceived non-response from the conventional temperature charts (figure.) 


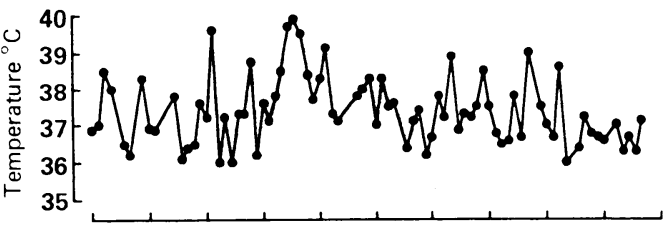

Top: Standard temperature chart of febrile patient with neutropenia; bottom: cusum distribution of temperature point with $37 \cdot 6^{\circ} \mathrm{C}$ as reference temperature, showing trend to reduced temperature with addition of fucidin

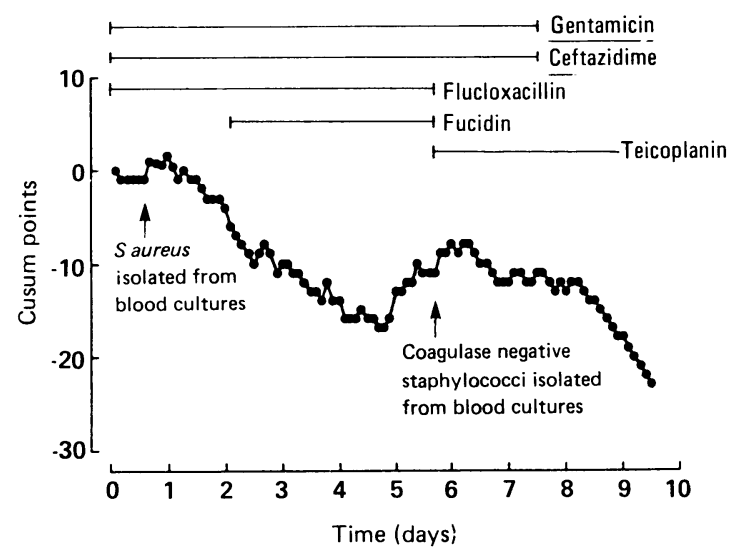

\section{Comment}

Cusum plotting is clinically useful when a fever is swinging wildly and the overall trend is hidden, when other antimicrobial agents are given that are therapeutically unnecessary, and in patients in whom temperature remains raised but generally static. It indicates worsening of the fever despite antimicrobial treatment and thus discloses ineffective treatment. In this study the overall trend of fever was more easily seen with cusum plotting and timing of empirical antifungal treatment was easier. In neutropenic patients who fail to respond to treatment with broad spectrum antibiotics empirical antifungal treatment is started on the fifth or sixth day of fever. This study also showed that when patients remain febrile (that is, the gradient of the cusum plot does not change appreciably) defervescence was achieved within $24-48$ hours after addition of antifungal agents.

Prospective cusum plotting of temperature indicates almost immediately failure of empirical antibacterial agents or the need for empirical antifungal treatment and thus has a place in day to day management of fever in neutropenic patients.

1 Bodey GP, Buckley M, Sathe YS, et al. Quantitative relationships between circulating leukocytes and infection in patients with acute leukaemia. circulating leukocytes and infect

2 Griffen DF. Systems control by cumulative sum method. American fournal of Medical Technologv 1968;34:1968.

3 Chaput de Saintonge DM, Vere DW. Why don't doctors use cusums? Lancet 1974;: :120-1.

4 Wohl $\mathrm{H}$. The cusum plot: it's utility in the analysis of clinical data. $N$ Engl 7 Med 1977;296: 1044-5.

5 W'alters S, Griffin GE. Resolution of fever in Staphylococcus aureus septicaemia-retrospective analysis by means of cusum plot. Fournal Infect 1986;12:57-63.

Accepted 2 fune 1989

\section{Safety of Picolax (sodium picosulphate-magnesium citrate) in inflammatory bowel disease}

\author{
A J G McDonagh, P Singh, W J Pilbrow, \\ G R Youngs
}

Departments of Medicine and Radiology, Chester Royal Infirmary, Chester CH1 2AZ

A J G McDonagh, MRCP, medical registrar

P Singh, MRCP, medical registrar

W J Pilbrow, FRCR, consultant radiologist G R Youngs, FRCP, consultant physician

Correspondence to: $\mathrm{Dr}$ A J G McDonagh, Royal Hallamshire Hospital, Sheffield S10 2JF.

BrMed F 1989;299:776-7
The widespread policy of restricting the dose of laxatives when preparing the bowel of patients with known or suspected inflammatory bowel disease for fear of severe adverse effects or of exacerbating the disease often results in poor colonic cleansing and the need for repeated tests. During the 1980 s Picolax (sodium picosulphate $10 \mathrm{mg} / \mathrm{sach}$ et with magnesium citrate formed in solution) has become established as the usual laxative for preparing the bowel before radiology or endoscopy in the United Kingdom. It is effective' and has milder adverse effects than the older sennosides and cascara..$^{23}$

In a survey of current practice among consultant members of the North of England Gastroenterology Society we found that 103 out of 117 respondents used Picolax for routine bowel preparation. In inflammatory bowel disease, however, their policy varied widely: 88 respondents adjusted the dose of laxative according to the severity of colitis, 19 invariably omitted the laxative, and 10 used the full dose even in severe colitis.

To test the hypothesis that Picolax is tolerated well in inflammatory bowel disease we undertook a survey of its adverse effects.

\section{Patients, methods, and results}

Over nine months consecutive medical outpatients and inpatients requiring a barium enema, sigmoidoscopy, or colonoscopy were prepared with a low residue diet for 48 hours and full dose Picolax (two sachets taken according to the manufacturer's instruc- tions). All completed a questionnaire about symptoms immediately before taking Picolax and again immediately before examination. Information was obtained about the effects of bowel preparation on abdominal pain and stool frequency and about the overall nuisance caused. Nuisance and abdominal pain were graded as absent, mild, moderate, or severe. During the study four inpatients with severe acute colitis were deemed unfit for investigation.

The $\chi^{2}$ test was used in group comparisons of results for abdominal pain and nuisance. Mean stool frequencies were compared by the standard error of the difference.

Out of 267 examinations, 55 were in patients with inflammatory bowel disease ( 48 with ulcerative colitis and seven with Crohn's disease). The table summarises the results. The frequency of increased abdominal pain and severe nuisance after Picolax was similar in the patients with inflammatory bowel disease and the patients with other colonic disorders. Interestingly, none of the patients with iron deficiency in whom investigations had yielded negative results reported severe nuisance; this was significantly different from the proportion reporting severe nuisance among the patients with inflammatory bowel disease $\left(\chi^{2}=4.05\right.$ with Yates's correction, $\mathrm{p}<0.05)$, the irritable bowel syndrome $\left(\chi^{2}=8.3\right.$ with Yates's correction, $\left.\mathrm{p}<0.01\right)$, and diverticular disease $\left(\chi^{2}=4.9\right.$ with Yates's correction, $\mathrm{p}<0.05)$. The increase in the mean number of stools/24 hours after Picolax was lower in the patients with inflammatory bowel disease than in the other diagnostic groups $(p<0 \cdot 05)$. On review two to four weeks after examination none of the patients with inflammatory bowel disease reported deterioration in their symptoms.

\section{Comment}

There is no unequivocal evidence that patients with inflammatory bowel disease are at increased risk from bowel preparation with laxatives, ${ }^{4}$ and in our study 